\title{
PENGARUH KETEBALAN LAPISAN DENTIN TERHADAP KEKUATAN FLEKSURAL PADA GIGI TIRUAN CEKAT KERAMIK-LOGAM
}

\author{
Susi Marlina R. Silalahi ${ }^{1}$, Vivie Zahara ${ }^{1}$, Sopan Sinamo ${ }^{2}$ \\ ${ }^{1}$ Mahasiswa Kedokteran Gigi ${ }^{2}$ Dosen Departemen Prostodonsia \\ Fakultas Kedokteran Gigi \\ Universitas Prima Indonesia, Medan \\ Email: sopansinamo@unprimdn.ac.id
}

\begin{abstract}
ABSTRAK
GTC keramik-logam adalah gigi tiruan cekat dengan bahan keramik-logam yang secara permanen disemenkan pada gigi geligi, dan sampai saat ini menjadi gold standard di Bidang Prostodontik, akan tetapi sering terjadi permasalahan pada GTC keramik-logam antara lain fraktur adhesi dan fraktur kohesi. Penelitian ini bertujuan untuk mengetahui pengaruh ketebalan lapisan dentin terhadap kekuatan fleksural pada GTC keramik-logam. Metode penelitian yang digunakan adalah eksperimental laboratorium secara in vitro, dengan rancangan penelitian post test only control group design. Jumlah sampel yang digunakan adalah sebanyak 27 sampel yang dibagi menjadi 3 kelompok, dimana masing-masing kelompok terdiri dari lapisan dentin $0,5 \mathrm{~mm}, 0,6 \mathrm{~mm}$, dan $0,7 \mathrm{~mm}$. Hasil penelitian ini menunjukkan nilai rata-rata kekuatan fleksural pada GTC keramik-logam pada ketebalan lapisan dentin 0,5 mm adalah 95,32 $\mathrm{MPa}, 0,6 \mathrm{~mm}$ adalah 101,68 MPa, dan 0,7 $\mathrm{mm}$ adalah 104,30 MPa. Kesimpulan penelitian ini menunjukkan bahwa semakin tebal lapisan dentin maka dapat menghasilkan kekuatan fleksural yang optimal.
\end{abstract}

Kata Kunci: GTC keramik-logam; lapisan opak; lapisan dentin; lapisan enamel; kekuatan fleksural

\section{PENDAHULUAN}

Dewasa ini, Gigi Tiruan Cekat (GTC) banyak digunakan sebagai salah satu solusi perawatan pada kasus kehilangan gigi. ${ }^{(12)}$ GTC merupakan gigi tiruan yang secara permanen disemenkan pada gigi geligi. Berdasarkan bahan, GTC diklasifikasikan menjadi tiga yaitu keramik penuh, logam penuh dan keramik-logam. ${ }^{(1)}$

Salah satu permasalahan yang sering terjadi pada GTC keramik-logam adalah fraktur yang berupa fraktur adhesi dan fraktur kohesi. Hal ini dapat mengakibatkan masalah fungsional maupun masalah estetik, sehingga untuk memperbaiki kembali GTC keramik-logam membutuhkan penggantian secara keseluruhan. ${ }^{(2)}$ Untuk mencegah terjadinya fraktur pada GTC keramik-logam diperlukan mekanisme perlekatan yang baik. Mekanisme perlekatan antara struktur keramik dan logam terjadi akibat adanya ikatan mekanis, gaya kompresi, gaya van der waals dan ikatan kimia. ${ }^{(3)}$

Beberapa faktor yang dapat mempengaruhi kekuatan ikatan antara keramik dan logam yaitu surface treatment logam, ketebalan lapisan logam dan jenis logam. Logam yang digunakan pada GTC keramik-logam harus tahan terhadap fraktur, memiliki modulus elastisitas yang tinggi, rigiditas, tahan terhadap deformasi permanen, biokompatibel, tahan terhadap korosi serta mudah dimanipulasi selama proses pembuatan gigi tiruan. ${ }^{(5)(6)}$

Nikel-kromium $(\mathrm{Ni}-\mathrm{Cr})$ yaitu logam yang paling umum digunakan pada GTC keramik-logam, akan tetapi $\mathrm{Ni}$ - $\mathrm{Cr}$ memiliki potensi terhadap masalah kesehatan, sehingga kobalt-kromium $(\mathrm{Co}-\mathrm{Cr})$ digunakan sebagai pilihan yang tepat. ${ }^{(7)}$ Adapun keuntungan 
penggunaan $\mathrm{Co}-\mathrm{Cr}$ dalam kedokteran gigi yaitu memiliki modulus elastisitas yang tinggi, memiliki kekuatan ikatan yang adekuat antara keramik dan logam, serta resisten terhadap korosi. Ketebalan yang optimal pada lapisan logam yaitu $0,2-0,7 \mathrm{~mm} .{ }^{(1)(6)}$

Faktor lain yang juga dapat mempengaruhi kekuatan keramik dan logam antara lain desain restorasi, teknik kondensasi, proses pembakaran keramik dan ketebalan lapisan keramik. Lapisan keramik memiliki tiga lapisan yaitu lapisan keramik pertama yang akan menutupi logam adalah lapisan opak, berperan penting dalam perkembangan ikatan antara keramik dan logam dan memulai penyesuaian warna. Lapisan opak diaplikasikan dengan ketebalan 0,1-0,3 mm. ${ }^{(1)}$

Lapisan kedua yaitu lapisan dentin merupakan lapisan yang akan menutup lapisan opak serta berfungsi sebagai penghubung pada lapisan enamel. Lapisan dentin berperan dalam membentuk ketebalan restorasi serta memberikan sebagian besar warna dan diaplikasikan dengan ketebalan 0,5 - 1,0 mm. Lapisan keramik ketiga yaitu lapisan enamel berfungsi memberikan translusensi pada GTC keramik-logam dengan ketebalan $0,1-0,7 \mathrm{~mm}^{\left({ }^{(8)}(1)\right.}$

Keramik memiliki stabilitas warna, biokompatibilitas, dan ketahanan terhadap aus, akan tetapi memiliki kekuatan fleksural yang rendah. ${ }^{14}$ Penelitian Son et al., (2010) mengenai pengaruh ketebalan lapisan dentin terhadap warna pada GTC keramik penuh, mengatakan bahwa hasil akhir warna yang sesuai pada GTC keramik penuh di dapat dengan memvariasikan ketebalan lapisan dentin. de Vasconcellos et al., (2010) melakukan penelitian tentang temperatur pembakaran ketebalan lapisan opak terhadap kekuatan fleksural pada GTC dengan bahan dasar logam $\mathrm{Co}-\mathrm{Cr}$, dimana hasil penelitian tersebut mengatakan bahwa peningkatan temperatur pembakaran pada lapisan opak dapat meningkatkan kekuatan fleksural pada GTC dengan bahan dasar logam $\mathrm{Co}-\mathrm{Cr}$.

Menurut Trindade, et al. (2014), kekuatan fleksural umumnya digunakan untuk mengetahui kekuatan ikatan antara lapisan keramik dengan logam. Untuk menentukan kekuatan fleksural tersebut maka perlu dilakukan uji fleksural yaitu berupa three point bending yang terdiri dari logam dan lapisan keramik kemudian di uji kekuatan fleksuralnya dengan menggunakan Universal Testing Machine. ${ }^{(10)}$

Berdasarkan penjelasan diatas, perlu diketahui bahwa untuk mendapatkan kekuatan perlekatan yang baik maka diperlukan ketebalan lapisan yang optimal pada setiap lapisan GTC keramik-logam, oleh sebab itu peneliti tertarik untuk mengevaluasi pengaruh variasi ketebalan lapisan dentin terhadap kekuatan fleksural pada GTC keramik-logam dengan bahan dasar logam $\mathrm{Co}-\mathrm{Cr}$.

\section{BAHAN DAN METODE}

Desain penelitian yang digunakan adalah eksperimental laboratorium secara in vitro, dengan rancangan penelitian post test only control group design. Sampel terdiri dari logam $\mathrm{Co}-\mathrm{Cr}$ dengan ukuran panjang $(25 \pm 1) \mathrm{mm} \times$ lebar $(3 \pm 0,1) \mathrm{mm} \times$ tinggi $(0,7 \pm 0,05) \mathrm{mm}$, dan porselen dengan ukuran panjang $(8 \pm 0,1) \mathrm{mm} \times$ lebar $3 \mathrm{~mm}$ $\times$ tinggi $(1,1 \pm 0,1) \mathrm{mm}$ yang akan di lapisi diatas tengah logam, yang berjumlah 27 sampel terdiri dari 3 kelompok perlakuan dengan ketebalan lapisan dentin yang berbeda-beda yaitu $0,5 \mathrm{~mm}$, $0,6 \mathrm{~mm}$ dan $0,7 \mathrm{~mm}$.

Alat dan bahan yang digunakan dalam penelitian ini adalah model induk, kaliper, alat burning, alat casting, alat sandblasting, alat ultrasonic cleaning, brush, agate spatula, glass slab, mata bur pinset, moffel, crucible tongs, vakum furnace, pelebur wax, Universal testing machine (TENSILON), gips tipe $\mathrm{V}$, Wax dan Vaselin, Akrilik self curing bubuk dan cairan, Malam spru, Investment gypsum. Logam $\mathrm{Co}-\mathrm{Cr}$, Bahan sandblasting, air destilasi, bubuk dan cairan porselen (Vita VMK Master ${ }^{\circledR}$ ), Bahan glazing (Vita AKZENT ${ }^{\circledR}$ Plus).

\section{Pengukuran Kekuatan Fleksural dengan Universal Testing Machine}

(1) Kekuatan fleksural diukur menggunakan universal testing machine pada alat three-point bending, dengan meletakkan sampel pada alat dimana kedua ujung sampel ditumpu pada jarak $(20 \pm 0,1) \mathrm{mm}$. (2) Penekanan pada sampel dilakukan secara konstan 1,5 $\mathrm{mm} /$ menit dengan memberikan beban pada bagian tengah sampel dengan jarak $(1,0 \mathrm{~mm} \pm$ $0,1)$. 
(3) Gaya fraktur (F) diukur pada saat terjadinya retak ikatan pada lapisan keramik dan dicatat secara digital dengan computer software. (4) Permulaan terjadinya kegagalan pada uji three point bending dapat dihitung dengan menggunakan rumus sebagai berikut: $\tau=\mathrm{k} \mathrm{x}$ Ffail. Dimana Ffail adalah gaya maksimum yang diaplikasikan pada saat terjadi retak atau terlepas (beban kegagalan) dan $\mathrm{k}$ adalah konstanta yang ditentukan dari ketebalan dan modulus elastisitas logam dan didapatkan dari grafik pada standar ISO 9693;2012.

\section{HASIL}

Nilai rata-rata kekuatan fleksural pada GTC keramik-logam dengan bahan dasar logam $\mathrm{Co}-\mathrm{Cr}$ pada setiap ketebalan lapisan dentin dijelaskan pada Tabel 1

Tabel 1 Nilai rata-rata kekuatan fleksural pada GTC keramik-logam dengan bahan dasar logam $\mathrm{Co}-\mathrm{Cr}$

\begin{tabular}{|c|c|c|}
\hline $\begin{array}{c}\text { Ketebalan } \\
\text { Lapisan } \\
\begin{array}{c}\text { Dentin } \\
(\mathrm{mm})\end{array}\end{array}$ & $\mathrm{n}$ & $\overline{\mathrm{X}} \pm \mathrm{SD}(\mathrm{MPa})$ \\
\hline 0,5 & 9 & $95,323 \pm 21,245$ \\
\hline 0,6 & 9 & $101,689 \pm 18,239$ \\
\hline 0,7 & 9 & $104,306 \pm 24,083$ \\
\hline
\end{tabular}

Berdasarkan Tabel 1 diatas, menunjukkan bahwa rata-rata kekuatan fleksural pada ketebalan lapisan dentin $0,5 \mathrm{~mm}$ adalah 95,323 $\pm 21,245 \quad \mathrm{MPa}, \quad 0,6 \mathrm{~mm}$ adalah $101,689 \pm 18,239 \mathrm{MPa}$, dan $0,7 \mathrm{~mm}$ adalah $104,306 \pm 24,083 \mathrm{MPa}$.

Untuk mengetahui data berdistribusi secara normal atau tidak maka dilakukan uji normalitas dengan Shapiro-Wilk seperti berikut:

Tabel 2. Normalitas data kekuatan fleksural pada GTC keramik-logam dengan bahan dasar logam $\mathrm{Co}-\mathrm{Cr}$ berdasarkan uji Shapiro-Wilk

\begin{tabular}{|c|c|c|}
\hline \multirow{2}{*}{$\begin{array}{c}\text { Lapisan dentin } \\
(\mathrm{mm})\end{array}$} & \multicolumn{2}{|c|}{ Shapiro wilik } \\
\cline { 2 - 3 } & $\mathrm{n}$ & $\mathrm{p}$ \\
\hline 0,5 & 9 & 0,068 \\
\hline 0,6 & 9 & 0,689 \\
\hline 0,7 & 9 & 0,681 \\
\hline
\end{tabular}

Berdasarkan Tabel 2. diatas, data hasil pengukuran kekuatan fleksural pada GTC keramik-logam dengan bahan dasar logam $\mathrm{Co}-\mathrm{Cr}$ pada ketebalan lapisan dentin $0,5 \mathrm{~mm}$ adalah $0,068,0,6 \mathrm{~mm}$ adalah 0,689 dan $0,7 \mathrm{~mm}$ adalah 0,681 . Hal ini menyatakan data berdistribusi secara normal $(\mathrm{p}>0,05)$.

Hasil uji t-test independen pengaruh ketebalan lapisan dentin $0,5 \mathrm{~mm}$ dan $0,6 \mathrm{~mm}$ terhadap kekuatan fleksural pada GTC keramiklogam dengan bahan dasar logam $\mathrm{Co}-\mathrm{Cr}$ dapat dilihat pada tabel 2:

Tabel 2. Nilai rata-rata dan standar deviasi berdasarkan uji t-test independen ketebalan lapisan dentin 0,5 dan 0,6 (mm)

\begin{tabular}{|c|c|c|}
\hline $\begin{array}{c}\text { Lapisan } \\
\text { Dentin } \\
(\mathrm{mm})\end{array}$ & $\begin{array}{c}\text { Rata-rata Kekuatan } \\
\text { Fleksural Keramik } \\
\text { Logam } \\
(\overline{\mathrm{X}} \pm \mathrm{SD})\end{array}$ & $\mathrm{p}$ \\
\hline 0,5 & $95,323 \pm 21,245$ & \multirow{2}{*}{0,505} \\
\hline 0,6 & $101,689 \pm 18,239$ & \\
\hline
\end{tabular}

Berdasarkan Tabel 2 diatas, menunjukkan bahwa rata-rata kekuatan fleksural pada GTC keramik-logam dengan bahan dasar logam $\mathrm{Co}-\mathrm{Cr}$ pada ketebalan lapisan dentin 0,5 $\mathrm{mm}$ adalah $95,323 \pm 21,245$ dan $0,6 \mathrm{~mm}$ adalah $101,689 \pm 18,239$. Berdasarkan analisis data menunjukkan nilai $\mathrm{p}=0,505 \quad(\mathrm{p}>0,05)$ yang berarti tidak ada pengaruh ketebalan antara lapisan dentin $0,5 \mathrm{~mm}$ dengan $0,6 \mathrm{~mm}$ terhadap kekuatan fleksural pada GTC keramik-logam dengan bahan dasar logam $\mathrm{Co}-\mathrm{Cr}$.

Pengaruh ketebalan antara lapisan dentin 0,5 $\mathrm{mm}$ dan 0,7 mm terhadap kekuatan fleksural pada GTC keramik-logam dengan bahan dasar logam $\mathrm{Co}-\mathrm{Cr}$ dijelaskan pada Tabel 3:

Tabel 3. Nilai rata-rata dan standar deviasi berdasarkan uji t-test independen 
ketebalan lapisan dentin $0,5 \mathrm{~mm}$ dan $0,7 \mathrm{~mm}$

\begin{tabular}{|c|c|c|}
\hline $\begin{array}{c}\text { Lapisan } \\
\text { dentin } \\
(\mathrm{mm})\end{array}$ & $\begin{array}{c}\text { Rata-rata kekuatan } \\
\text { fleksural keramik-logam } \\
(\overline{\mathrm{X}} \pm \mathrm{SD})\end{array}$ & $\mathrm{p}$ \\
\cline { 1 - 2 } 0,5 & $95,323 \pm 21,245$ & \multirow{2}{*}{0,558} \\
\hline 0,7 & $104,306 \pm 24,083$ & \\
\hline
\end{tabular}

Berdasarkan Tabel 3. diatas, menunjukkan bahwa nilai rata-rata kekuatan fleksural pada GTC keramik-logam dengan bahan dasar logam $\mathrm{Co}-\mathrm{Cr}$ pada ketebalan lapisan dentin $0,5 \mathrm{~mm}$ adalah $95,323 \pm 21,245$, dan 0,7 $\mathrm{mm}$ adalah 104,306 $\pm 24,083$. Berdasarkan analisis data menunjukkan nilai $\mathrm{p}=0,558$ $(\mathrm{p}>0,05)$ yang berarti tidak ada pengaruh ketebalan lapisan dentin $0,5 \mathrm{~mm}$ dengan $0,7 \mathrm{~mm}$ terhadap kekuatan fleksural pada GTC keramiklogam dengan bahan dasar logam $\mathrm{Co}-\mathrm{Cr}$.

Pengaruh ketebalan lapisan dentin 0,6 $\mathrm{mm}$ dan $0,7 \mathrm{~mm}$ terhadap kekuatan fleksural pada GTC keramik-logam dengan bahan dasar logam $\mathrm{Co}-\mathrm{Cr}$ dijelaskan pada Tabel 4:

Tabel 4 Nilai rata-rata dan standar deviasi berdasarkan uji t-test independen ketebalan lapisan dentin $0,6 \mathrm{~mm}$ dan $0,7 \mathrm{~mm}$

\begin{tabular}{|c|c|c|}
\hline $\begin{array}{c}\text { Lapisan } \\
\text { dentin } \\
(\mathrm{mm})\end{array}$ & $\begin{array}{c}\text { Rata-rata kekuatan } \\
\text { fleksural keramik-logam } \\
(\overline{\mathrm{X}} \pm \mathrm{SD})\end{array}$ & $\mathrm{p}$ \\
\hline 0,6 & $101,689 \pm 18,239$ & 0,789 \\
\hline 0,7 & $104,306 \pm 24,083$ & \\
\hline
\end{tabular}

Berdasarkan Tabel 4 diatas, menunjukkan bahwa nilai rata-rata kekuatan fleksural pada GTC keramik-logam dengan bahan dasar logam $\mathrm{Co}-\mathrm{Cr}$ pada ketebalan lapisan dentin $0,6 \mathrm{~mm}$ adalah $101,689 \pm 18,239$, dan 0,7 $\mathrm{mm}$ adalah 104,306 $\pm 24,083$. Berdasarkan analisis data menunjukkan nilai $\mathrm{p}=0,789$ $(p>0,05)$ yang berarti tidak ada pengaruh ketebalan lapisan dentin $0,6 \mathrm{~mm}$ dan $0,7 \mathrm{~mm}$ terhadap kekuatan fleksural pada GTC keramik logam dengan bahan dasar logam $\mathrm{Co}-\mathrm{Cr}$.

Untuk mengetahui ketebalan lapisan dentin yang menghasilkan kekuatan fleksural paling optimal pada GTC keramik-logam dengan bahan dasar logam $\mathrm{Co}-\mathrm{Cr}$, maka dilakukan analisis dengan uji oneway anova yang dapat dilihat pada Tabel 5.

Tabel 5. Ketebalan lapisan dentin yang menghasilkan kekuatan fleksural paling optimal pada GTC keramik-logam dengan bahan dasar logam $\mathrm{Co}-\mathrm{Cr}$ berdasarkan uji oneway anova signifikansi $\mathrm{p}<0,05$

\begin{tabular}{|c|c|c|c|}
\hline \multirow{2}{*}{$\begin{array}{c}\text { Ketebalan } \\
\text { lapisan } \\
\text { dentin } \\
(\mathrm{mm})\end{array}$} & $\begin{array}{c}|c| \\
\text { Rata- } \\
\text { rata }\end{array}$ & $\mathrm{SD}$ & $\begin{array}{c}p \\
\text { value }\end{array}$ \\
\hline 0,5 & 95,323 & 21,245 & \multirow{2}{*}{0,660} \\
\hline 0,6 & 101,689 & 20,632 & \multirow{2}{*}{0,660} \\
\hline 0,7 & 104,306 & 24,083 & \\
\hline
\end{tabular}

Berdasarkan Tabel 5. diatas, menunjukkan bahwa nilai rata-rata kekuatan fleksural pada GTC keramik-logam dengan bahan dasar logam $\mathrm{Co}-\mathrm{Cr}$ dengan ketebalan lapisan dentin $0,5 \mathrm{~mm}$ adalah $95,323 \pm 21,245$, lapisan dentin $0,6 \mathrm{~mm}$ adalah $101,689 \pm 18,239$, dan lapisan dentin $0,7 \mathrm{~mm}$ adalah $104,306 \pm 24,083$. Berdasarkan analisis data ketiga kelompok dengan menggunakan Uji Oneway Anova didapatkan nilai $\mathrm{p}=0,660$ $(\mathrm{p}>0,05)$ yang berarti tidak terdapat perbedaan bermakna antara ketiga kelompok.

Rata-rata kekuatan fleksural pada GTC keramik-logam dengan bahan dasar logam $\mathrm{Co}-\mathrm{Cr}$ pada ketebalan setiap lapisan dentin memiliki perbedaan rata-rata yang bervariasi pada tiap kelompok, hal ini menunjukkan bahwa lapisan dentin dengan ketebalan 0,7 $\mathrm{mm}$ dapat memberikan kekuatan fleksural paling optimal pada GTC keramik-logam dengan bahan dasar logam $\mathrm{Co}-\mathrm{Cr}$.

\section{PEMBAHASAN}

Hasil penelitian menunjukkan rata-rata kekuatan fleksural pada ketebalan setiap lapisan dentin $(0,5 \mathrm{~mm}, 0,6 \mathrm{~mm}$ dan $0,7 \mathrm{~mm})$ menunjukkan nilai yang bervariasi pada setiap kelompok. Hasil penelitian ini telah 
membuktikan bahwa terdapat peningkatan kekuatan fleksural dengan meningkatnya ketebalan lapisan dentin, namun peningkatan tersebut secara statistik tidak memiliki pengaruh yang signifikan. Menurut Kavan et al. (2015) salah satu faktor yang dapat terjadi saat prosedur laboratorium yaitu ukuran partikel pada saat prosedur sandblast dapat mempengaruhi kekuatan antara keramik dan logam, dimana semakin besar ukuran partikel yang digunakan untuk prosedur sandblast maka semakin bagus kekuatan yang dihasilkan.

Berdasarkan hasil uji $t$-test independen menunjukkan bahwa ketebalan lapisan dentin 0,5 $\mathrm{mm}, 0,6 \mathrm{~mm}$ dan $0,7 \mathrm{~mm}$ tidak memiliki pengaruh terhadap kekuatan fleksural pada GTC keramik-logam dengan bahan dasar logam $\mathrm{Co}$ Cr. Trindade, et al., (2013) dalam penelitiannya mengatakan bahwa agen bonding tidak memiliki pengaruh dalam meningkatkan kekuatan fleksural keramik-logam. Hasil penelitian ini tidak sesuai dengan penelitian yang dilakukan Kavut dan Külünk (2019) yang mengatakan ada pengaruh ketebalan lapisan keramik terhadap kekuatan fleksural pada GTC.

Berdasarkan hasil oneway Anova menunjukkan bahwa tidak terdapat perbedaan bermakna pada ketebalan lapisan dentin $0,5 \mathrm{~mm}$, $0,6 \mathrm{~mm}$ dan $0,7 \mathrm{~mm}$ terhadap kekuatan fleksural pada GTC keramik-logam dengan bahan dasar logam $\mathrm{Co}-\mathrm{Cr}$. Menurut teori Shillingburg, et al., (2012) lapisan dentin berperan dalam membentuk ketebalan restorasi dengan ketebalan yang optimal antara $0,5 \mathrm{~mm}-1 \mathrm{~mm}$. Penelitian ini hanya mengevalusi pengaruh kekuatan fleksural pada ketebalan lapisan dentin $0,5 \mathrm{~mm}, 0,6 \mathrm{~mm}$ dan 0,7 mm. Oleh karena itu, pengujian kekuatan fleksural pada GTC keramik-logam dapat dilakukan pada ketebalan lapisan dentin yang berbeda. Selain itu penelitian ini juga hanya mengevaluasi kekuatan fleksural pada satu jenis keramik yaitu keramik VITA VMK Master dan satu jenis logam yaitu logam $\mathrm{Co}-\mathrm{Cr}$, oleh sebab itu pengujian kekuatan fleksural pada GTC keramik-logam dapat dilakukan pada jenis keramik dan logam yang berbeda.

Kekuatan fleksural pada ketebalan lapisan keramik berkisar antara 62-90 MPa. Pada penelitian ini rata-rata kekuatan fleksural paling optimal pada GTC keramik-logam dengan bahan dasar logam $\mathrm{Co}-\mathrm{Cr}$ adalah 104,30 MPa. Oleh sebab itu, dapat memberikan manfaat ataupun masukan bagi para dokter gigi, khususnya prostodonti mengenai ketebalan lapisan dentin yang sesuai terhadap kekuatan fleksural pada GTC keramik-logam.

\section{KESIMPULAN}

Berdasarkan hasil dan pembahasan diperoleh beberapa kesimpulan antara lain:

(1) Tidak ada perbedaan peningkatan kekuatan fleksural yang signifikan pada GTC keramik-logam dengan bahan dasar logam $\mathrm{Co}^{-}$ $\mathrm{Cr}$. (2) Terdapat peningkatan kekuatan fleksural dengan meningkatnya ketebalan lapisan dentin, namun peningkatan tersebut secara statistik tidak memiliki pengaruh yang signifikan.

\section{SARAN}

Diperlukan penelitian lebih lanjut untuk menguji pengaruh ketebalan lapisan dentin terhadap kekuatan fleksural pada GTC keramiklogam dengan ketebalan lapisan dentin $0,8 \mathrm{~mm}$, $0,9 \mathrm{~mm}$ dan $1,0 \mathrm{~mm}$.

\section{DAFTAR PUSTAKA}

1. Shillingburg HT, Sather DA, Wilson EL, Cain J.R, et al. Fundamentals of Fixed Prosthodontics. $\quad 4^{\text {th }}$ edition. USA: Quintessence Publishing Co, Inc, 2012, pp. 81-3, 447-69.

2. Aslam A, Hassan S, Nayyer M, Ahmed B. Intraoral repair protocols for fractured metal-ceramic restorations - Literature review. South African Dent J. 2018;73(1):35-41.

3. Zeighami S, Hemmati YB, Falahchai SM. Effect of Ceramic Thickness and Cement Color on Final Shade of all ceramic restorations: a systematic review. Scholars Academic Journal of Biosciences (SAJB). 2017. 5 (6). pp 425-432.

4. de Vasconcellos LGO, Buso L, Lombardo GHL, Souza ROA, Nogueira Júnior L, Bottino MA, et al. Opaque layer firing temperature and aging effect on the flexural strength of ceramic fused to cobaltchromium alloy. J Prosthodont. 2010;19(6):471-7. 
5. Kavut I. Evaluation of the Core Thickness and Resin Cement on the Fracture Strength of Zirconia - Based Multilayer Computer - Aided Design Computer - Aided Manufacturing Ceramic Crowns. 2019;(January).

6. Matos AO, Branco C de CCC, Klautau EB, Alves BP. Comparative analysis of ceramic flexural strength in co-cr and ni-cr alloys joined by TIG welding and conventional brazing. Brazilian J Oral Sci. 2017;16:1-9.

7. Babu PJ, Alla RK, Alluri VR, Datla SR, Konakanchi A. Dental Ceramics: Part I - An Overview of Composition, Structure and Properties. Am J Mater Eng Technol. 2015;3(1):13-8.

8. Giannarachis C, Marmandiu C, Gabriel V, Vasilescu E, Patrascu I. Review Article Metal-Ceramic Bond in Merging Ceramic Mass on Metal Component. 2013;(2):5-12.

9. 60812 I. International Standard International Standard. 61010-1 (C) Iec2001. 2006;2006:13.

10. Kassapidou M, Franke Stenport V, Hjalmarsson L, Johansson CB. Cobaltchromium alloys in fixed prosthodontics in Sweden. Acta Biomater Odontol Scand [Internet]. 2017;3(1):53-62. Available from: https://doi.org/10.1080/23337931.2017.136 0776

11. Patel KA, Mathur S, Upadhyay S. A comparative evaluation of bond strength of feldspathic porcelain to nickel - chromium alloy, when subjected to various surface treatments: An in vitro study. 2015;15(1):53-7.

12. Powers JM, Wataha JC. Dental Materials Properties and Manipulation. St. Louis, Missouri : Elsevier Mosby. 2012,pp. 133-48.

13. Son HJ, Kim WC, Jun SH, Kim YS, Ju SW, Ahn JS. Influence of dentin porcelain thickness on layered all-ceramic restoration color. J Dent [Internet]. 2010;38(SUPPL. 2):e71-7. Available from:http://dx.doi.org/10.1016/j.jdent.2010. 08.007

14. Sinamo S, Tamin HZ, Agusnar H. Influenceof Opaque with Dentine Layer Thickness to Color Matching on MetalCeramic Crown. 2016;15(12):1-7.

15. Trindade FZ, Anami LC, da Costa Lima JM, de Vasconcellos LGO, Balducci I, Júnior $\mathrm{LN}$, et al. The effect of a bonding agent and thermo-mechanical cycling on the bond strength of a glass-ceramic to gold and cobalt-chromium alloys. Appl Adhes Sci. 2014;2(1).

16. White SN, Miklus VG, McLaren EA, Lang LA, Caputo AA. Flexural strength of a layered zirconia and porcelain dental allceramic system. J Prosthet Dent. 2005;94(2):125-31 